\title{
As repercussóes no cotidiano de máes de bebês internados na Unidade de Terapia Intensiva Neonatal no isolamento social devido à COVID-19 1
}

\section{The repercussions in daily routine of mothers of babies admitted in Neonatal Intensive Care Unit in social isolation caused by COVID-19}

\author{
Amanda Leão da Silveira Rocha ${ }^{a}$ (D), Erika da Silva Dittz ${ }^{a}$ (D) \\ ${ }^{a}$ Universidade Federal de Minas Gerais - UFMG, Belo Horizonte, MG, Brasil.
}

Como citar: Rocha, A. L. S., \& Dittz, E. S. (2021). As repercussóes no cotidiano de mães de bebês internados na Unidade de Terapia Intensiva Neonatal no isolamento social devido à COVID-19. Cadernos Brasileiros de Terapia Ocupacional. 29, e2158. https://doi.org/10.1590/2526-8910.ctoAO2158

\begin{abstract}
$\underline{\text { Resumo }}$
Introduçáo: A pandemia causada pelo novo Coronavírus trouxe repercussôes para o cenário mundial e as principais formas de controle da doença têm sido as medidas de prevenção, nas quais se insere o isolamento social. A necessidade de isolamento modifica o funcionamento típico das famílias e impacta no seu cotidiano, além das repercussões psicológicas e sociais inerentes ao contexto. Vivenciar esse momento de pandemia concomitante à internação do recém-nascido contribui para o distanciamento materno do seu cotidiano e pode impactar negativamente em seu psiquismo. Objetivo: Conhecer as repercussōes do isolamento social no cotidiano de mães de bebês internados na Unidade de Terapia Intensiva Neonatal (UTIN) durante a pandemia por COVID-19. Método: Estudo descritivo-exploratório de abordagem qualitativa, realizado em um Hospital filantrópico de Belo Horizonte, Minas Gerais, com a participação de 15 mães de bebês internados na UTIN. Utilizou-se entrevista semiestruturada e os dados foram submetidos à análise de conteúdo na modalidade temática. Resultados: Verificou-se que as mães possuem conhecimentos e informaçóes gerais sobre a COVID-19 e percebem as mudanças que passaram a fazer parte do cotidiano. Os aspectos emocionais relacionados à condição de ter um bebê internado na UTIN foram intensificados, além de repercutir na forma como as mães participavam do cuidado do bebê. Conclusáo: A pandemia trouxe repercussóes no cotidiano dessas máes e reconhece-se a necessidade de fornecer informaçóes eficazes, proporcionar às famílias um local de escuta ativa e auxiliar no manejo do próprio cuidado e do cuidado do bebê de forma segura, favorecendo as ocupaçôes relativas à maternidade.
\end{abstract}

Palavras-chave: Terapia Ocupacional, Mães, Atividades Cotidianas, Unidades de Terapia Intensiva Neonatal, COVID-19.

${ }^{1} \mathrm{O}$ material é parte de pesquisa, aprovado pelo Comitê de Ética em Pesquisa do Hospital Sofia Feldman (parecer noo. 4.057.433). 


\section{$\underline{\text { Abstract }}$}

Introduction: The new coronavirus pandemic has reverberated in the world scenario and the main forms of disease control are preventive measures, which include social isolation. The need for isolation promotes changes in the family behavior and impacts their daily lives, in addition to the psychological and social repercussions inherent to the context. Experiencing the pandemic during the newborn hospitalization contributes to the maternal distance from her daily life and can negatively impact her psyche. Objective: This study aims to know the repercussions of social isolation in the daily lives of mothers with babies admitted to the Neonatal Intensive Care Unit (NICU) during the COVID-19 pandemic. Method: Descriptive-exploratory study with a qualitative approach, carried out in a philanthropic hospital in Belo Horizonte, Minas Gerais, with 15 mothers of babies admitted to the NICU as participants. Semi-structured interviews were used and the data were submitted to content analysis in the thematic modality. Results: It was found that mothers have general knowledge and information about COVID-19 and realize the changes that have been incorporated into their daily life. The emotional aspects related to the condition of having a baby admitted to the NICU were intensified reflecting on the way mothers participated in baby care. Conclusion: The pandemic has had repercussions on the mother's daily lives and the need to provide effective information was identified. In addition, there was a need to provide families with an active listening place, and assistance in the safe management of their own and baby care, favoring occupations related to maternity.

Keywords: Occupational Therapy, Mothers, Activities of Daily Living, Intensive Care Units, Neonatal, COVID-19.

\section{Introduçáo}

Um novo tipo de Coronavírus (SARS-CoV-2) foi confirmado em 7 de janeiro de 2020 pelas autoridades chinesas, após identificar um aumento no número de casos de pneumonia na cidade de Wuhan, na China. Esse novo Coronavírus é responsável por causar a doença COVID-19, a qual foi caracterizada como uma pandemia, em 11 de março de 2020 (Organização Panamericana de Saúde, 2020; World Health Organization, 2020b).

Segundo o Ministério da Saúde (Brasil, 2020), os sintomas mais comuns da COVID-19 são febre, tosse seca, coriza, dor de garganta e dificuldade para respirar. Cerca de $80 \%$ das pessoas infectadas desenvolvem casos leves da doença, porém, em outros casos, a doença pode ser mais grave, o que leva à necessidade de tratamento hospitalar de alta complexidade (Organização Panamericana de Saúde, 2020). A transmissão desse vírus acontece de uma pessoa contaminada para outra, e ocorre por meio de gotículas de saliva, aperto de mão, tosse, espirros, catarro e/ou objetos ou superfícies contaminadas, caracterizando, assim, sua alta capacidade de contágio (Brasil, 2020).

Um dificultador no controle da doença é a ausência de vacina, sendo que as medidas têm focado na sua prevenção, reunindo as seguintes recomendaçóes: lavar as mãos frequentemente com água e sabão ou utilizar desinfetante à base de álcool; ao tossir ou espirrar, cobrir a boca e o nariz com o cotovelo flexionado ou com um lenço de papel que deve ser descartado logo em 
seguida; manter a distância de um metro entre outras pessoas; e evitar tocar olhos, nariz e boca. Difundidos por todo o mundo, o uso de máscaras de proteção e o isolamento social também têm sido formas de prevenção contra o novo Coronavírus (World Health Organization, 2020b).

No Brasil, a informação que temos até o momento é de que a identificação do primeiro caso da COVID-19 ocorreu em 26 de fevereiro de 2020, sendo diversas medidas de controle e prevençáo tomadas pelas autoridades sanitárias locais, dentre as quais está o isolamento social (Croda \& Garcia, 2020).

Entende-se por isolamento social uma intervenção que pode ser aplicada à determinada comunidade, região ou até mesmo a uma cidade inteira, com o intuito de reduzir interaçôes e movimentação entre pessoas. Essa medida envolve desde o distanciamento social, com o fechamento de escolas, comércios, serviços não essenciais e cancelamento de eventos públicos, até o bloqueio completo de atividades de uma cidade (Schuchmann et al., 2020). Nesse contexto, o indivíduo deixa de participar de atividades sociais em grupo, como o trabalho e o lazer.

A necessidade de permanecer em casa é uma medida que modifica o funcionamento típico das famílias e repercute no seu cotidiano, podendo acarretar impactos consideráveis à dinâmica pessoal e familiar. Estudos acerca dos efeitos associados ao isolamento social relatam a existência de impactos sociais e psicológicos, durante e após o isolamento, sendo os principais: alteraçóes no sono (Bezerra et al., 2020); frustração, tédio e insegurança (Brooks et al., 2020); preocupação (World Health Organization, 2020a); impactos financeiros e no convívio social (Bezerra et al., 2020; Brooks et al., 2020); medo e estresse (Bezerra et al., 2020; Brooks et al., 2020; World Health Organization, 2020a).

As repercussôes sociais e psicológicas associadas ao isolamento podem ser exacerbadas em decorrência do momento vivenciado por cada pessoa, como é a situação das famílias que passam pelo processo de hospitalização de um recém-nascido em uma Unidade de Terapia Intensiva Neonatal (UTIN).

Nesse contexto, as famílias, especialmente as mães, lidam com a necessidade de se adaptar a uma rotina hospitalar e se distanciam, mesmo que momentaneamente, da sua principal fonte de apoio - a família (Souza et al., 2009; Costa et al., 2010). No isolamento social, essa situação pode ser potencializada em decorrência do plano de contingenciamento adotado, tanto pelo município quanto pela instituição na qual o bebê está internado, sendo frequente a restrição no número de pessoas circulando nos serviços de saúde, limitando ou suspendendo as visitas. Nesses casos, a mãe, que permanece na instituição acompanhando o bebê internado, distancia-se do convívio com familiares, podendo impactar negativamente em seu psiquismo (Silva et al., 2020).

Pode-se constatar que as medidas de isolamento social repercutem diretamente no cotidiano das pessoas, influenciando o que elas fazem, como elas vivem, quais atividades realizam e como se inserem no mundo. No que tange ao campo da terapia ocupacional, há o reconhecimento de que cada pessoa vive o cotidiano de forma particular, levandose em conta a singularidade do sujeito e o seu contexto social (Salles \& Matsukura, 2013). Pelo exposto, situaçôes que evidenciam uma ruptura na vida cotidiana se tornam foco de atenção do terapeuta ocupacional, com vistas a apoiar as pessoas no processo de reconstruir e ressignificar sua vida cotidiana diante dessa nova realidade que se apresenta. 
Essa problemática apresentada, apreciada à luz da medida atualmente vigente de isolamento social no contexto da pandemia por COVID-19, desperta a necessidade de conhecer as repercussóes da pandemia na vida das pessoas, fornecendo subsídios para a estruturação do serviço de saúde de forma a atender às necessidades de cuidado desse grupo.

Pelo exposto, este estudo tem o objetivo de conhecer as repercussóes do isolamento social no cotidiano de mães de bebês internados na UTIN durante a pandemia por COVID-19.

\section{Método}

Trata-se de uma pesquisa com abordagem qualitativa que buscou desvelar processos sociais que ainda são pouco conhecidos e que pertencem a grupos particulares, sendo seu objetivo e indicação final proporcionar a construção e/ou revisão de novas abordagens, conceitos e categorias referentes ao fenômeno estudado (Minayo, 2013).

O estudo é sustentado pelo referencial teórico do cotidiano de Heller (2000), o qual adota o entendimento de que é na vida cotidiana que se produzem as relaçóes sociais entre os homens e onde são reproduzidas as atividades e culturas existentes.

O estudo foi realizado na Fundação de Assistência Integral à Saúde - Hospital Sofia Feldman -, em Belo Horizonte, Minas Gerais, a qual é especializada na assistência maternoinfantil e que atende, exclusivamente, usuários do Sistema Único de Saúde (SUS). Além dos leitos obstétricos, a instituição conta com 51 leitos de Unidade de Terapia Intensiva Neonatal (UTIN) e disponibiliza condiçôes para permanência das mães em período integral durante a internaçáo do recém-nascido na UTIN - o Espaço de Sofias.

Para a inclusão das participantes, foram adotados os seguintes critérios: mães com permanência no Espaço de Sofias por, no mínimo, seis dias e com bebês internados na UTIN por, no mínimo, oito dias. Considerando a média de 17 dias de internação no primeiro trimestre de 2020 (Hospital Sofia Feldman, 2020), esse primeiro critério se justifica por entender que tal período se trata de um momento necessário para a mãe vivenciar o novo cotidiano decorrente da necessidade de acompanhar o bebê hospitalizado. Foram excluídas do estudo mães usuárias de álcool e drogas ilícitas; com distúrbios psíquicos e instabilidade emocional constatada, por meio de verificação no formulário de acolhimento realizado pela equipe de psicologia e arquivado no prontuário do recém-nascido.

As participantes foram identificadas a partir do censo diário realizado no Espaço de Sofias. Em seguida, foram consultados os prontuários dos recém-nascidos internados na UTIN para obter informaçóes sobre a idade gestacional, evolução clínica e data de internação do bebê, além de coletar informaçóes sobre a história materna.

A coleta de dados ocorreu no período de 30 de maio a 19 de junho e teve início após aprovação do Comitê de Ética em Pesquisa do Hospital Sofia Feldman (parecer no 4.057.433), atendendo às determinaçóes da Resolução no 466/2012 (Brasil, 2012) e no 580/2018 (Brasil, 2018). As participantes foram informadas do objetivo do estudo e foi solicitada a assinatura do Termo de Consentimento Livre e Esclarecido. A entrevista foi realizada em local seguro, garantindo a privacidade, confidencialidade e integridade, e no momento de escolha da participante, de forma a não comprometer sua participação nos cuidados do recém-nascido ou interferir na sua rotina diária. Além disso, foram adotadas as medidas de segurança em relação à COVID-19, com o distanciamento de, no mínimo, um metro entre a pesquisadora e a entrevistada e o uso de máscara por ambas as partes.

Utilizou-se como instrumento para a coleta de dados a entrevista semiestruturada (Minayo, 2013), que seguiu o roteiro conforme apresentado na Tabela 1: 
Tabela 1. Perguntas norteadoras da entrevista.

1. O que você sabe sobre a pandemia de COVID-19?

2. Você identifica mudanças em sua vida devido à pandemia de COVID-19? O que mudou?

3. Fale-me um pouco como tem sido para você lidar com a pandemia de COVID-19 ao mesmo tempo que seu bebê está internado na UTIN?

4. Como você se sente tendo que lidar com a internação do seu bebê durante a pandemia de COVID-19?

5. Você tem tomado algum cuidado especial durante o tempo que está no hospital? Qual(is)?

A entrevista foi gravada e, imediatamente, transcrita na íntegra pela pesquisadora, constituindo um texto único referente a cada uma das participantes. Visando preservar o anonimato, as participantes foram identificadas com a letra " $\mathrm{M}$ ", seguida do código numérico referente à ordem de inclusão na pesquisa. Concomitante à coleta de dados, foi realizado um processo de análise preliminar e chegou-se à saturação dos dados ao se verificar a repetição de dados que permitiam responder ao objetivo do estudo (Thiry-Cherques, 2016).

Os dados obtidos com a entrevista foram analisados em seu conteúdo na modalidade temática (Bardin, 1979; Minayo, 2013) de acordo com as seguintes etapas: pré-análise, exploração do material, tratamento dos dados obtidos e interpretação. Assim, os dados foram explorados por duas pesquisadoras que realizaram a leitura da transcrição das entrevistas e destacaram temas centrais sobre o objeto de estudo. A partir dos temas identificados, foram definidas categorias empíricas e foi dada continuidade na exploraçáo do material, sendo a versão final das categorias apresentadas na Tabela 2:

Tabela 2. Categorias empíricas identificadas nos relatos das mães.

\section{Categorias:}

Acesso à informaçáo e conhecimento sobre a COVID-19 pelas máes de bebês internados na UTIN

Repercussōes no modo de viver o cotidiano associadas à COVID-19

Ser mãe de um bebê internado na UTIN em tempos de COVID-19

Ao longo do estudo, buscou-se atender os critérios de validação da pesquisa qualitativa (Moreira, 2018). O critério de confiabilidade foi atendido no processo de análise dos dados, sendo a categorização realizada por duas pesquisadoras que compararam os resultados, chegando a um consenso acerca das categorias empíricas. Para a confirmabilidade, realizou-se descrição detalhada de todo o processo de pesquisa, incluindo a definição dos participantes, os instrumentos de coleta de dados e o processo de análise, buscando o máximo possível de neutralidade, para reduzir o viés do pesquisador. Ademais, no processo de análise foram realizadas discussóes entre as pesquisadoras, para identificar percepçóes divergentes ou complementares, possibilitando explorar os dados em profundidade. A credibilidade foi estabelecida por meio da triangulação teórica, oferecendo múltiplas perspectivas para interpretar um conjunto de dados.

\section{Resultados e Discussáo}

Participaram do estudo 15 mães com idade entre 19 e 37 anos, sendo que todas frequentaram a escola em uma média de 11 anos e apenas uma pertencia ao município de Belo Horizonte, o 
que demonstra a referência do Hospital para o Estado de Minas Gerais. A permanência no Espaço de Sofias variou entre oito e 98 dias, podendo-se evidenciar que as mães com tempo de permanência superior a 30 dias relatam menos mudanças no cotidiano. Esse dado pode estar relacionado ao fato de já vivenciarem o distanciamento do domićlio em decorrência da necessidade de permanecer no ambiente hospitalar acompanhando o bebê. Entre os recémnascidos, a média de idade gestacional foi de 29 semanas e 5 dias e o peso variou de 620 gramas a 2.605 gramas. $\mathrm{Na}$ Tabela 3, há a caracterizaçáo mais detalhada de cada participante.

Tabela 3. Caracterização das mães e recém-nascidos participantes do estudo.

\begin{tabular}{|c|c|c|c|c|c|c|}
\hline Máe & $\begin{array}{c}\text { Idade } \\
\text { Materna }\end{array}$ & $\begin{array}{c}\text { Escolaridade } \\
\text { materna (em anos) }\end{array}$ & Procedência & $\begin{array}{c}\text { Tempo de } \\
\text { permanência no } \\
\text { Espaço de Sofias }\end{array}$ & $\begin{array}{l}\text { Idade Gestacional do } \\
\text { recém-nascido ao } \\
\text { nascimento (em } \\
\text { semanas) }\end{array}$ & $\begin{array}{c}\text { Peso do recém-nascido } \\
\text { ao nascimento }\end{array}$ \\
\hline M1 & 22 & 12 anos & Formiga & 75 dias & 28 semanas e 3 dias & $1480 \mathrm{~g}$ \\
\hline M2 & 28 & 14 anos & Moeda & 50 dias & 28 semanas e 4 dias & $620 \mathrm{~g}$ \\
\hline M3 & 19 & 12 anos & Corinto & 89 dias & 35 semanas e 1 dia & $2470 \mathrm{~g}$ \\
\hline M4 & 25 & 12 anos & Nova Lima & 34 dias & 26 semanas & $935 \mathrm{~g}$ \\
\hline M5 & 36 & 12 anos & João Monlevade & 13 dias & 28 semanas e 3 dias & $850 \mathrm{~g}$ \\
\hline M6 & 35 & 12 anos & Sabará & 8 dias & 38 semanas & $2605 \mathrm{~g}$ \\
\hline M7 & 34 & 12 anos & Bom Sucesso & 24 dias & 28 semanas e $1 \mathrm{dia}$ & $1140 \mathrm{~g}$ \\
\hline M8 & 21 & 12 anos & Curvelo & 19 dias & 26 semanas e 5 dias & $980 \mathrm{~g}$ \\
\hline M9 & 22 & 9 anos & Matipó & 22 dias & 32 semanas e $1 \mathrm{dia}$ & $1390 \mathrm{~g}$ \\
\hline M10 & 28 & 11 anos & Moema & 26 dias & 32 semanas e 5 dias & $1635 \mathrm{~g}$ \\
\hline M11 & 33 & 11 anos & Brumadinho & 55 dias & 30 semanas & $665 \mathrm{~g}$ \\
\hline M12 & 29 & 6 anos & Itatiaiuçu & 64 dias & 28 semanas e 6 dias & $1010 \mathrm{~g}$ \\
\hline M13 & 37 & 10 anos & Nova Serrana & 98 dias & 24 semanas & $700 \mathrm{~g}$ \\
\hline M14 & 24 & 12 anos & $\begin{array}{l}\text { Santana do } \\
\text { Riacho }\end{array}$ & 21 dias & 31 semanas & $1100 \mathrm{~g}$ \\
\hline M15 & 37 & 16 anos & Belo Horizonte & 35 dias & 27 semanas & $925 \mathrm{~g}$ \\
\hline
\end{tabular}

A análise dos dados possibilitou o agrupamento em categorias, as quais serão discorridas a seguir.

\section{Acesso à informação e conhecimento sobre a COVID-19 pelas mães de bebês internados na UTIN}

Essa categoria evidenciou sobre o acesso das mães a informaçóes e os conhecimentos adquiridos por elas acerca da COVID -19 tanto no que se refere a medidas preventivas quanto às incertezas sobre o vírus.

Dentre as mães participantes, onze delas disseram possuir algum conhecimento acerca da pandemia. Aspectos como o local de origem do vírus, sua alta taxa de transmissibilidade, os sintomas causados e a possibilidade de levar à morte foram relatados pelas mães.

É uma coisa, no meu ver ataca muito as vias respiratórias da gente. Aí causa falta de ar, entendeu? Eu penso também que não sei se pode dá pneumonia né, mas é tipo como se fosse uma pneumonia bem, bem grave mesmo. (M2). 
Eu sei que é um vírus né, que veio, surgiu lá na China e que veio se espalhando pelo mundo inteiro. (M4).

É uma doença recente, onde atingiu o mundo todo, que ela é altamente prejudicial, altamente é... transmissivel né, não por suor que eu saiba, mas por saliva, respiração essas coisas. (M5).

Eu sei é que a COVID é um vírus que tá matando muita gente no mundo. (M14).

Apesar de permanecerem em tempo integral no ambiente hospitalar, as mães evidenciaram que a principal fonte de informaçáo acerca da pandemia era por meio da televisão disponibilizada no Espaço de Sofias.

Como a gente tem a televisão lá no Espaço Sofias, então a gente fica sabendo, infelizmente, ou felizmente não sei, de tudo que tá se passando [...] a gente está assim bem por dentro da situação. (M1).

É o que estâo falando ai todo santo dia, toda hora, o dia inteiro. (M6).

Que eu sei é o que eu vejo na televisão, as mortes, os riscos e mais nada. E é difícil de ver né. (M9).

Estudo realizado por Santos et al. (2020) afirma que o acesso à informação clara e de qualidade é uma das estratégias mais eficazes para o enfrentamento da COVID-19, pois a informação empodera o sujeito para lidar com a situação da maneira mais adequada. No entanto, os principais meios de comunicação estão concentrados nas mãos de uma minoria, que determina o conteúdo a ser veiculado. Isso tem efeitos no exercício da cidadania da população, pois a comunicação se torna exclusiva para certo público e a informação pode ser alvo de notícias falsas. Estratégias de comunicação alternativa têm sido utilizadas para garantir informação de qualidade e com embasamento científico de forma compreensível para todos, porém, a preferência se mantém nos meios de comunicação tradicionais e digitais (Associação Brasileira de Saúde Coletiva, 2020).

A desinformação, a difusão de mitos e informaçóes equivocadas, e a dificuldade de compreender as orientações das autoridades sanitárias podem provocar estados psicológicos de medo, desespero, ansiedade e depressão (Bú et al., 2020; Schmidt et al., 2020; Zandifar \& Badrfam, 2020). Diante disso, pode-se recomendar açóes educativas que contribuam para o acesso à informação segura e confiável, como rodas de conversa e dinâmicas temáticas. Além dessas ações, a produção de material específico voltado para o momento vivenciado por essas mães pode ser uma alternativa eficaz que contribui para um acesso à informação segura e confiável. Uma dessas produçôes é a cartilha de Joaquim \& Magalhães (2020), que é direcionada às gestantes, mães de recém-nascidos e crianças pequenas durante o cumprimento de medidas de distanciamento social, que contém orientaçóes para cuidados essenciais de proteção contra o contágio pelo Coronavírus, a reorganização da rotina, a necessária mudança de planos, entre outras.

As incertezas com relação ao Coronavírus, no que se refere à possibilidade de cura e tratamento, são expressas pelas participantes.

Eu sinto nele que eles [pesquisadores] estão tentando achar uma cura, mas ainda não conseguiu achar a cura pra ele ainda. (M2). 
[...] mas creio também que tem alguma cura que não foi divulgada ainda porque talvez não tenha assim, certeza que vai dá certo. (M8).

É um vírus que hoje ainda não tem tratamento. (M15).

A imprevisibilidade da situação e as incertezas da gravidade da doença, como controlá-la e um possível tratamento e/ou imunização podem se configurar como fatores de risco à saúde mental da população em tempos de pandemia (Bú et al., 2020).

As informaçóes disponíveis permitem que as mães adquiram um conhecimento acerca das medidas para evitar a contaminaçáo pela COVID-19. Os relatos evidenciam que novos hábitos, termos e recomendaçóes passaram a fazer parte do cotidiano das mães.

A gente está usando a máscara para as gotículas minha não cair no rosto de outra pessoa, se eu estiver contaminada passar para outra pessoa também. (M2).

Igual estâo aí falando, todo dia falam da gente ter o cuidado de manter distância, uso de máscara, ter o cuidado de higiene, com as mãos para que a gente náo se contamine. (M6).

O certo é lavar as mãos, ficar isolado, mas infelizmente é uma coisa que eu não estou podendo no momento. (M7).

Com vistas a reduzir o contágio pelo novo Coronavírus, torna-se necessária a adoção consciente das medidas de precaução, as quais exigem uma mudança de comportamento individual e coletivo, o que acarreta rupturas na vida cotidiana. Estudos como os de Oliveira et al. (2020) e Mercês et al. (2020) e as recomendaçôes da Organização Mundial de Saúde (World Health Organization, 2020b) reforçam a importância de medidas preventivas com o objetivo de conter o avanço da doença. Dentre essas medidas, destacam-se o isolamento social horizontal, higiene das mãos com água e sabão ou álcool 70\%, o uso da máscara de proteção, etiqueta respiratória, cobrindo nariz e boca ao tossir ou espirrar, ventilaçáo de ambientes e o náo compartilhamento de objetos pessoais (Mercês et al., 2020; Oliveira et al., 2020).

Tendo em vista o contexto vivenciado mundialmente em decorrência da pandemia de COVID-19, as mudanças ocorridas com a incorporação de novos hábitos pelas mães se sustentam no entendimento que a vida cotidiana está no centro da história, sendo influenciada pelos acontecimentos, repercutindo na cotidianidade e em como ela irá se manifestar ao longo dos tempos (Heller, 2000). Assim, os acontecimentos marcantes da vida estão impressos no cotidiano e as mudanças subjetivas e objetivas que acontecem com o sujeito atravessam a vida cotidiana (Salles \& Matsukura, 2013).

\section{Repercussóes no modo de viver o cotidiano associadas à COVID-19}

As mães participantes do estudo percebem as mudanças ocorridas e relatam as medidas de prevenção à COVID-19 que passaram a fazer parte do cotidiano, sendo que houve uma unanimidade em relaçáo ao uso da máscara e da higiene das mãos, mas também foi mencionada a restrição de circulação na área externa ao hospital.

Então tem que lavar a mão, usar a máscara e evitar ficar rondando aqui no hospital. (M3). 
Máscara o dia inteiro, lavar a mão toda hora, toda hora que a gente vai se alimentar, toda hora que você vai mexer com a criança [...] o máximo de cuidado, é lógico. E é trocando de máscara, não ficando com a máscara muito tempo, revezando. (M6).

Coisa que eu não teria... que não tenho costume de fazer antes da pandemia que é ficar lavando a mão todo tempo, usando álcool, máscara... assim. Até mesmo com a própria roupa, roupa que vai na rua eu não entro lá na UTI. (M12).

Percebe-se que o cenário mundial, ao demandar mudanças no modo de vida para reduzir o risco de contágio, leva a mãe a adotar novas rotinas e hábitos, característicos da cotidianidade (Benetton et al., 2003). De acordo com Salles \& Matsukura (2013), após o aparecimento de uma doença, a vida cotidiana pode tomar outro rumo: o que antes era importante pode se tornar secundário, ou uma atividade que antes era realizada com facilidade pode se tornar um desafio e novas aprendizagens podem ser necessárias.

$\mathrm{O}$ fato de o bebê estar internado na UTIN parece intensificar a preocupação por parte das mães em relação às medidas preventivas contra a COVID-19.

É... é isso de você se precaver, de você pensar... não é você, é o seu bebê que está na UTI. É de se lavar quando precisar. (M11).

De ficar tomando banho toda hora, que eu acho que quando eu vou lá nela, eu fico com medo... eu tomo banho aí eu deş̧o, ai dá umas duas vezes que eu já fui lá aí subo de novo para tomar banho, porque tipo assim, a gente não sabe, mas toda hora passa um e outro, pode passar alguma coisa pra gente. Como ela está na UTI qualquer coisa pega infecção. Então é melhor ir bem limpo para lá. (M3).

Cabe destacar que há sentimentos que podem ser considerados como inerentes à condição de ter um bebê internado na UTIN, como culpa, aflição, angústia, ansiedade, medo, impotência, instabilidade emocional e insegurança (Frello \& Carraro, 2012; Baseggio et al., 2017). Assim, além do estresse vivenciado pela hospitalização de um filho, o contexto de pandemia pode exacerbar tais sentimentos (Guinancio et al., 2020).

Essa situação demanda um olhar atento para as necessidades maternas, sendo recomendadas intervençóes que podem contribuir para minimizar esses sentimentos vivenciados pelas mães, bem como fortalecê-la para lidar com essa situação. Visando à redução do estresse materno, algumas estratégias se configuram como fundamentais para este objetivo. Pode-se citar a relaçáo interpessoal entre equipe-mãe-bebê, a qual é pautada na comunicação efetiva, na conversa, acolhimento e carinho, oferecendo suporte e favorecendo a relação de confiança entre ambos (Frello \& Carraro, 2012). Os grupos de apoio também constituem uma prática eficaz para a redução do estresse, pois promovem o acolhimento da família em suas demandas emocionais e uma vivência transformadora a partir do compartilhamento de experiências, da formação de rede de apoio, do esclarecimento de dúvidas e da inclusão da família no cuidado do neonato (Balbino et al., 2015). Dentre os grupos de apoio estão os grupos de terapia ocupacional, cuja relação terapeuta-atividade-membros se volta para a organização dos fazeres cotidianos, colocando-os em uma posição central, valorizando suas açôes e contribuindo para a reduçáo da ansiedade (Correia et al., 2019).

Atrelada à condição de maior estresse, a necessidade de implantação de medidas de restrição de circulação de pessoas na cidade e instituição aumentou o distanciamento 
dos familiares, que configuram a rede de apoio dessa mãe. As participantes do estudo percebem o impacto dessa restrição e relatam o quão importante é esse apoio familiar durante a internação do bebê na UTIN.

É difícil porque a gente queria ter o apoio da familia, poder receber um familiar e não tem como por causa do vírus, porque eu acho que é muito importante, a gente ter o apoio da familia, mas com essa pandemia, atrapalhou um pouco. (M4).

Se tivesse o pai mais perto, a familia mais perto eu acho que seria mais fácil da gente passar por esse momento difícil que cada uma aqui passa e está passando. (M6).

O que mudou é o isolamento, tipo meu menino nasceu, minha mãe não pôde vir ver ele [...]. É o isolamento total da família mesmo, está sendo um momento muito triste pra mim. (M7).

Eu me sinto às vezes desprotegida, desprotegida que eu falo no sentido de pensar nele [filho] aqui na UTIN e também pensar nos meus entes queridos que estäo em casa, que muitas das vezes precisam sair pra trabalhar, que... a vida ainda não parou. (M11).

De acordo com Exequiel et al. (2019), as mães vivenciam fortemente o sofrimento por precisar se manter longe do marido e dos outros filhos, gerando preocupaçóes quanto à manutenção do seu lar e do cuidado com o restante de sua família, bem como as dificuldades para lidar com a saudade e o afastamento da sua rede de apoio.

De acordo com Heller (2000, p. 17), "a vida cotidiana é a vida de todo homem" e o homem amadurece na sua cotidianidade pela interação que estabelece com os grupos aos quais pertence. Ainda segundo a autora, "[...] são partes orgânicas da vida cotidiana a organização do trabalho e da vida privada, os lazeres e o descanso, a atividade social sistematizada, o intercâmbio e a purificação".

Em situaçóes de crise e emergência, como a do Coronavírus, é importante considerar as mudanças experimentadas nas rotinas sociais, familiares e de trabalho considerando aspectos que são comuns a todas as mães e outros que tratam da particularidade de cada uma delas, ou seja, "[...] o indivíduo é sempre, simultaneamente, ser particular e ser genérico [...]” (Heller, 2000, p. 20). Reconhecer essa característica de indissociabilidade do indivíduo é o que irá orientar a construção de projetos terapêuticos que possam repercutir no modo como as mães vivem seu cotidiano no contexto de pandemia.

Durante a pandemia, são impostas dificuldades na manutenção dessa rede de apoio, uma vez que há restrição de deslocamento e circulação interna e externa. Assim, a mãe expressa sentimento de impotência, não só pela internação do recém-nascido, mas também pelas mudanças no seu cotidiano e no âmbito familiar. Dentre essas mudanças, destaca-se a preocupação das mães que possuem outros filhos em casa e a necessidade de que eles permaneçam sob os cuidados de outro familiar (Lima \& Smeha, 2019). Corroborando esse estudo, algumas mães que participaram do presente estudo expressam o sentimento de se sentirem divididas entre eles e o medo de contaminá-los.

Às vezes eu fico preocupada aqui, como eu tenho outros filhos lá fora eu fico preocupada com eles também. Ai fica assim, dividido entre os dois. (M13).

Primeiro eu estou evitando ir na minha casa né, porque eu tenho mais três filhos além da que está aqui, eu tenho mais três filhos sendo que dois são pequenos ainda. (M15).

Os relatos das mães evidenciam que as medidas de prevenção à COVID-19 modificaram seu cotidiano, seja no trabalho, seja no contato afetivo com pessoas 
próximas, na convivência com o outro. Mudanças no modo como passaram a realizar as atividades relacionadas a seus hábitos e rotinas foram também relatadas por elas.

Mudou o modo da gente poder fazer uma compra, o modo de sair de casa, o modo de cumprimentar as pessoas, de viver mesmo com as pessoas. (M4).

Mudou muito a rotina, o jeito de lidar dentro de casa. A gente tem que estar tendo mais cuidado com algumas coisas, para gente manusear... alimentos, frutas. Mudou muita coisa, Nossa Senhora! Mudou coisa demais da conta na rotina do dia a dia da gente. (M6).

Mudou sim, mas mais para mim foi no meu local de trabalho [...] que eu trabalhava, trabalho em supermercado como atendente de SAC [serviço de atendimento ao consumidor], então igual eu trabalhava guardando as coisas então toda hora eu tinha que guardar, limpar a mão ou então usar luva, entendeu? (M8).

A gente saía, no domingo mesmo a gente saía em familia, eu recebia, fazia um almoço em casa. Agora evitar o máximo né, o máximo até de sair, só se for necessário mesmo. (M12).

Porque sempre quando a gente se via, era um abraço né. O nosso primeiro contato era um abraço, então o abraço ele tá fazendo falta né. Essa forma de contato mais... juntinho, está fazendo falta. (M11).

Benetton et al. (2003) e Galheigo (2003) expóem que a vida cotidiana é uma sequência de acontecimentos vividos no dia a dia, o centro da práxis, na qual se produzem e reproduzem as relaçóes sociais. Takatori (2001) traz em seu conceito que o cotidiano é uma forma de viver sua própria história, possibilitando ao sujeito expor seu estilo de ser, que, ao mesmo tempo, é compartilhado e reconhecido pelo outro, construindo sua história social.

O cotidiano engloba os fazeres humanos e inclui atividades como o cuidado de si e dos outros, os afazeres domésticos, o lazer, a participaçáo social, sendo que a importância dessas atividades varia ao longo do dia ou da vida. As cenas do dia a dia servem de testemunho de um espaço-tempo moldado pela cultura, pelas histórias de vida e pelas relaçóes sociais (Galheigo, 2020). Essas ideias acerca do cotidiano estão em concordância com dados obtidos no estudo, ao indicar que tais cenas da vida cotidiana foram afetadas no contexto da pandemia. O modo como as mães passaram a realizar as atividades cotidianas foi modificado, uma vez que medidas de distanciamento social e higiene passaram a ocupar um lugar dominante na hierarquia de atividades que compunham o seu cotidiano.

\section{Ser mãe de um bebê internado na UTIN em tempos de COVID}

A terceira categoria evidenciou aspectos emocionais acerca do ser mãe de um bebê internado na UTIN e como os cuidados com os recém-nascidos foram afetados devido à pandemia de COVID-19.

As mães relatam o medo que sentem do bebê ser contaminado, uma vez que ele já convive com o risco inerente ao fato de ter nascido prematuramente. Esse sentimento intensifica nelas as preocupaçôes em relação às medidas de higiene antes de ter contato com o bebê na UTIN.

Por mais que tenha os cuidados todos é muito medo, só medo que eu estou tendo. (M7).

Acaba que a gente não pensa na gente, pensa no filho, mas ai toma as precauçöes para a gente, para não ter que passar para o bebê, porque ele já não está numa situação muito 
boa né, na UTI, então a gente tem medo né, porque contagiar um nenenzinho daquele tamanho não tem como né. Então é... é um pouco difícil sim. (M8).

Então a gente fica com aquele certo medo, ainda mais sendo prematurinha [...] pelo fato deles ser prematuros, ai você já coloca na cabeça, mesmo que eu pudesse, com essa pandemia, igual eu estou te falando, se fosse pra tomar banho de álcool eu acho que nem assim a gente se sentiria limpa. (M5).

As mães trazem relatos que evidenciam os sentimentos que caracterizam o momento pelo qual estão passando. O medo é um sentimento que está presente no cotidiano delas, e por vezes vem acompanhado de impotência, angústia e tristeza.

Ai, a palavra é impotente. Impotente porque não depende nada de mim, eu não posso fazer nada né, eu só tenho que esperar, então eu me sinto impotente, é a palavra certa é essa. (M1).

No hospital eu fico com mais medo porque tem muita aglomeração, querendo ou não, mesmo diminuindo tem ainda, né. Mas não tem jeito. (M3).

Muita tristeza e angústia. É só isso mesmo, tristeza e angústia demais, longe da família, só meu marido que vem nos finais de semana e mesmo assim eu fico com medo porque ele para nas estradas para comer. É um momento de terror que a gente está vivendo, eu acho. (M7).

Mais é insegurança mesmo, porque como eu te falei... é algo novo. Se pelo menos tivesse vacina ou algum tratamento realmente eficaz, mas tá ainda muito em fase de teste ainda, então assim a insegurança ainda é muito grande. (M15).

Ah tá sendo difícil, não tá sendo fácil não. Ah não, é muita coisa ao mesmo tempo, sabe. (M13).

As respostas psicossociais frente à pandemia podem diferir de um grupo para outro, pois estes enfrentam preocupaçóes e experiências únicas. No entanto, independente do grupo, os níveis de ansiedade, medo, irritabilidade e estresse tendem a se elevar significativamente em períodos de crise, como a do Coronavírus (Chew et al., 2020). No contexto da pesquisa, as mães entrevistadas vivenciam o momento de pandemia concomitante à internação do recém-nascido, sendo esta última uma situação que traz sentimentos negativos, como medo, impotência e desespero diante do sofrimento do filho (Dittz \& Rocha, 2018). Além desses, Lima \& Smeha (2019) relatam sentimentos de ambivalência que são comuns quando se vivencia a internação de um filho, como alegria/tristeza, esperança/desesperança, separação/apego e tristeza/felicidade.

É possível perceber a existência desses sentimentos ambivalentes nos relatos de duas mães que consideram o ambiente da UTIN como o mais seguro neste momento, uma vez que a alta hospitalar parece significar maior risco de contaminação do bebê por COVID-19.

Eu sinto que é mais seguro ele está aqui do que está lá fora. (M2).

Com o (nome do bebê) aqui dentro eu me sinto tranquila, apesar também que eu tenho medo, tenho inseguranças todas, mas com ele aqui dentro eu sinto mais... não é segura porque a gente também corre o risco de pegar né, a gente náo pode negligenciar isso, mas aqui eu me sinto segura com ele, em relaçâo a ele. (M11). 
Com vistas a auxiliar as mães no enfrentamento desses sentimentos de ambivalência, ressalta-se a importância de mantê-las orientadas quanto às medidas de restrição adotadas pela instituição e as medidas de prevenção contra o contágio pelo Coronavírus, bem como garantir o cuidado e acompanhamento multiprofissional para a díade famíliabebê durante toda a internação.

O receio de contaminar o bebê pelo COVID-19 também é relatado pelas mães como um dos motivos para evitar realizar alguns cuidados, como tocar ou segurar o bebê no colo, o que justifica, também, intensificar os cuidados pessoais básicos, de modo a evitar um possível contágio. Além disso, muitas dessas mães evitam o contato mais próximo do bebê com receio da contaminação.

Muito dificil, porque eu mesma fui pegar minha filha depois de dez dias que ela tinha nascido e mesmo pegando, tendo contato eu não podia dar um cheirinho, abraçar como a gente queria, dar um beijinho porque a gente tem que estar prevenida o tempo todo e proteger eles também, que já estão numa situação tão delicada, dentro do CTI, é assim bem complicado. (M1).

É difícil tipo eu tenho que sair às vezes pra ir numa farmácia, num supermercado e por mais que eu chego lavo as mão, tomo os cuidados todinho a gente fica com medo, mesmo assim a gente fica preocupada. (M7).

Eu tenho medo de quando ele ganhar alta que a gente sair lá pra fora, como que vai ser o cuidado meu com ele, como que vai ser o cuidado das pessoas pra chegar perto dele [...] como que vai ser a proteção do bebê, se a imunidade dele vai ser resistente a esse virus [...]. Igual esses dias eu ia fazer Canguru com ele, eu não fiz, porque como eu estava com a mesma blusa que en fui na rua eu falei, não vou fazer. Eu subi aqui, preferi tomar um banho ou tirar aquela blusa e colocar outra [...]. (M9).

Porque às vezes a gente quer ir lá ver ele e tudo, mas tem que ter cuidado então é um pouquinho difícil. Às vezes eu quero pegar, mas eu tenho medo. (M14).

[...] não fico pegando tanto a neném, mesmo com todos os cuidados de higiene e tudo eu evito ficar pegando muito nela. (M15).

Diante do exposto, açóes educativas contribuem para que a mãe se sinta mais segura e mantenha o contato próximo com seu bebê. Essas ações compóem o trabalho da equipe multiprofissional e age com vistas a apoiar a mulher na construçáo do papel materno. De acordo com Heller (2000), o indivíduo desenvolve capacidades diferentes na execução de tarefas diferentes e isso não se limita a trocar de papel, mas começa a mudar a si mesmo na medida em que a nova tarefa requer outras qualidades. Assumir o papel materno em tempos de pandemia da COVID-19 e manter os demais papéis sociais já implementados exige uma rica e mutável explicitação de suas habilidades. O dever-ser se converte em uma exigência puramente externa e exige adaptação de atitudes, as quais podem levar à recusa do papel. Essa recusa é inevitável na medida em que o homem náo submete incondicionalmente todo o seu ser ao papel que desempenha num dado momento (Heller, 2000), fato que pode ser agravado pela ruptura do cotidiano e mudanças da rotina perante o cenário de pandemia. Tendo em vista este contexto, a clínica da terapia ocupacional é criada no encontro de um cotidiano possível, pois ele é ou foi violentamente transformado, pela sua interrupção e não pela sua supressão (Benetton et al., 2003, p. 38). Dessa forma, inserimos nossa prática com vistas a auxiliar no manejo do cotidiano das mães que vivem a internaçáo do recém-nascido e no reconhecimento do papel materno durante a pandemia de COVID-19. 


\section{Conclusão}

As mães apresentam conhecimentos gerais sobre a COVID-19, mas percebe-se a necessidade de fornecer informaçóes confiáveis e direcionadas para o contexto delas. O cenário de pandemia trouxe repercussóes para o cotidiano das mães que acompanham a internaçáo do recém-nascido, impactando na dinâmica familiar, no próprio cuidado e no cuidado com o bebê. Importante considerar a execução da pesquisa com demais integrantes da família, bem como em serviços com protocolos de acesso dos pais à UTIN distintos do que é seguido pelo cenário deste estudo. A terapia ocupacional, sendo uma área que se fundamenta nas ocupaçóes do indivíduo, tem seu foco de atenção no apoio às mães no processo de reconstruir e ressignificar sua vida cotidiana, de forma a auxiliar no manejo do próprio cuidado e do cuidado com o bebê de forma segura, criando condiçóes para instaurar ou dar continuidade às ocupaçóes da maternidade durante a pandemia de COVID-19.

\section{Referências}

Associação Brasileira de Saúde Coletiva - ABRASCO. (2020). Comunicação popular e comunitária em tempos de Covid19: o direito de se comunicar e o direito à saúde. Rio de Janeiro: ABRASCO.

Balbino, F. S., Yamanaka, C. I., Balieiro, M. M. F. G., \& Mandetta, M. A. (2015). Grupo de apoio aos pais como uma experiência transformadora para a família em unidade neonatal. Escola Anna Nery Revista de Enfermagem, 19(2), 297-302.

Bardin, L. (1979). Análise de conteúdo. Lisboa: Edições 70.

Baseggio, D. B., Dias, M. P. S., Brusque, S. R., Donelli, T. M. S., \& Mendes, P. (2017). Vivências de mães e bebês prematuros durante a internaçáo neonatal. Temas em Psicologia, 25(1), 153-167.

Benetton, M. J., Tedesco, S., \& Ferrari, S. (2003). Hábitos, cotidiano e terapia ocupacional. Revista do Centro de Estudos de Terapia Ocupacional, 8(8), 27-40.

Bezerra, A. C. V., Silva, C. E. M., Soares, F. R. G., \& Silva, J. A. M. (2020). Fatores associados ao comportamento da populaçáo durante o isolamento social na pandemia de COVID-19. Ciencia \& Saude Coletiva, 25(1), 2411 2421. http://dx.doi.org/10.1590/1413-81232020256.1.10792020.

Brasil. (2012, 12 de dezembro). Resolução n 466, de 12 de dezembro de 2012. Aprova diretrizes e normas regulamentadoras de pesquisas envolvendo seres humanos. Diário Oficial [da] República Federativa do Brasil, Brasília. Recuperado em 21 maio 2020, de https://bvsms.saude.gov.br/bvs/saudelegis/cns/2013/res0466_12_12_2012.html

Brasil. (2018, 22 de março). Resoluçáo n ${ }^{\circ}$ 580, de 22 de março de 2018. Regulamenta o disposto no item XIII.4 da Resolução CNS no 466, de 12 de dezembro de 2012, que estabelece que as especificidades éticas das pesquisas de interesse estratégico para o Sistema Único de Saúde (SUS) serão contempladas em Resolução específica, e dá outras providências. Diário Oficial [da] República Federativa do Brasil, Brasília. Recuperado em 21 maio 2020, de https://conselho.saude.gov.br/resolucoes/2018/Reso580.pdf

Brasil. Ministério da Saúde. (2020). Coronavirus (COVID-19). Recuperado em 15 maio 2020, de https://coronavirus.saude.gov.br

Brooks, S. K., Webster, R. K., Smith, L., Woodland, L., Wessely, S., Greenberg, N., \& Rubin, G. J. (2020). The psychological impact of quarantine and how toreduce it: rapid review of the evidence. Lancet, 395(10227), 912920. http://dx.doi.org/10.1016/S0140-6736(20)30460-8.

Bú, E. A., Alexandre, M. E. S., Bezerra, V. A. S., Sá-Serafim, R. C. N., \& Coutinho, M. P. L. (2020). Representaçōes e Ancoragens Sociais do Novo Coronavírus e do Tratamento da COVID-19 por Brasileiros. Estudos de Psicologia, 37, e200073. http://dx.doi.org/10.1590/1982-0275202037e200073.

Chew, Q. H., Wei, K. C., Vasoo, S., Chua, H. C., \& Sim, K. (2020). Narrative synthesis of psychological and coping responses towards emerging infectious disease outbreaks in the general population: practical considerations for the COVID-19 pandemic. Singapore Medical Journal, 61(7), 350-356. http://dx.doi.org/10.11622/smedj.2020046.

Correia, L. A., Rocha, L. L. B., \& Dittz, E. S. (2019). Contribuições do grupo de terapia ocupacional no nível de ansiedade das mães com recém-nascidos prematuros internados nas unidades de terapia intensiva neonatal. Cadernos Brasileiros de Terapia Ocupacional, 27(3), 574-583. http://dx.doi.org/10.4322/2526-8910.ctoAO1694. 
Costa, M. C. G., Arantes, M. Q., \& Brito, M. D. C. (2010). A UTI Neonatal sob a ótica das mães. Revista Eletrônica de Enfermagem, 12(4), 698-704. http://dx.doi.org/10.5216/ree.v12i4.7130.

Croda, J. H. R., \& Garcia, L. P. (2020). Resposta imediata da Vigilância em Saúde à epidemia da COVID-19. Epidemiologia e Serviços de Saúde : Revista do Sistema Unico de Saúde do Brasil, 29(1), e2020002. http://dx.doi.org/10.5123/s1679-49742020000100021.

Dittz, E. S., \& Rocha, L. L. B. (2018). Terapia Ocupacional em unidades de terapia intensiva neonatal. In M. M. R. P. De Carlo \& A. M. Kudo. (Orgs.), Terapia ocupacional em contextos hospitalares e cuidados paliativos (pp. 311-328). São Paulo: Payá Eireli.

Exequiel, N., Milbrath, V., Gabatz, R., Vaz, J., Hirschmann, B., \& Hirschmann, R. (2019). Vivências da família do neonato internado em unidade de terapia intensiva. Revista Enfermagem Atual, 89(27), 1-9. https://doi.org/10.31011/reaid-2019-v.89-n.27-art.466.

Frello, A. T., \& Carraro, T. E. (2012). Enfermagem e a relação com mães de neonatos em Unidade de Terapia Intensiva Neonatal. Revista Brasileira de Enfermagem, 65(3), 514-521.

Galheigo, S. M. (2003). O cotidiano na terapia ocupacional: cultura, subjetividade e contexto histórico-social. Revista de Terapia Ocupacional da Universidade de Säo Paulo, 14(3), 104-109. http://dx.doi.org/10.11606/issn.22386149.v14i3p104-109.

Galheigo, S. M. (2020). Terapia ocupacional, cotidiano e a tessitura da vida: aportes teórico-conceituais para a construçáo de perspectivas críticas e emancipatórias. Cadernos Brasileiros de Terapia Ocupacional, 28(1), 5-25.

Guinancio, J. C., Sousa, J. G. M., Carvalho, B. L., Souza, A. B. T., Franco, A. A., Floriano, A. A., \& Ribeiro, W. A. (2020). COVID-19: desafios do cotidiano e estratégias de enfrentamento frente ao isolamento social. Research Social Development, 9(8), e259985474. http://dx.doi.org/10.33448/rsd-v9i8.5474.

Heller, A. (2000). O cotidiano e a história. São Paulo: Paz e Terra.

Hospital Sofia Feldman. (2020). Indicadores. Belo Horizonte: HSF.

Joaquim, R. H. V. T., \& Magalhães, L. C. (2020). Maternidade em tempos de COVID-19. Belo Horizonte: UFMG. Recuperado em 15 setembro 2020, de http://www.eeffto.ufmg.br/eeffto/DATA/UserFiles/files/Maternidade\%20em\%20tempos\%20do\%20COVIDFINAL.pdf

Lima, L. G., \& Smeha, L. N. (2019). A experiência da maternidade diante da internação do bebê na UTI: uma montanha russa de sentimentos. Psicologia em Estudo, 24, 1-14. http://dx.doi.org/10.4025/psicolestud.v24i0.38179.

Mercês, D. M., Abdias, G. S., Moreira, T. A., Lima, F. L. O., \& Neto, J. R. T. V. (2020). Doença de coronavírus 2019 (Covid-19): mecanismos, diagnóstico diferencial e influência das medidas de intervenção. Research Social Development, 9(8), e921986075. http://dx.doi.org/10.33448/rsd-v9i8.6075.

Minayo, M. C. S. (2013). O desafio do conhecimento: pesquisa qualitativa em saúde. São Paulo: Hucitec.

Moreira, H. (2018). Critérios e estratégias para garantir o rigor na pesquisa qualitativa. Revista Brasileira de Ensino de Ciência e Tecnologia, 11(1), 405-424.

Oliveira, A. C., Lucas, T. C., \& Iquiapaza, R. A. (2020). O que a pandemia da COVID-19 tem nos ensinado sobre adoção de medidas de precaução? Texto \& Contexto Enfermagem, 29, 1-15. http://dx.doi.org/10.1590/1980265X-TCE-2020-0106.

Organização Pan-americana de Saúde - OPAS. (2020). Folha informativa - COVID-19 (doença causada pelo novo coronavirus). Recuperado em 9 maio 2020, de

https:/www.paho.org/bra/index.php?option=com_content\&view=article\&id=6101:covid19\&Itemid=875

Salles, M. M., \& Matsukura, T. S. (2013). Estudo de revisão sistemática sobre o uso do conceito de cotidiano no campo da terapia ocupacional no Brasil. Cadernos de Terapia Ocupacional da UFSCar, 21(2), 265-273. http://dx.doi.org/10.4322/cto.2013.028.

Santos, I. S., Mariano, T., \& Pimentel, C. E. (2020). Psicologia da pandemia: informação, confiança e afetos durante o enfrentamento do COVID-19. Recuperado em 11 agosto 2020, de https:/www.researchgate.net/publication/341575564_Psicologia_da_Pandemia_Informacao_Confianca_e_Afet os_durante_o_Enfrentamento_do_COVID-19/citation/download

Schmidt, B., Crepaldi, M. A., Bolze, S. D. A., Neiva-Silva, L., \& Demenech, L. M. (2020). Saúde mental e intervençôes psicológicas diante da pandemia do novo coronavírus (COVID-19). Estudos de Psicologia, 37, 1-13. http://dx.doi.org/10.1590/1982-0275202037e200063. 
Schuchmann, A. Z., Schnorrenberger, B. L., Chiquetti, M. E., Gaiki, R. S., Raimann, B. W., \& Maeyama, M. A. (2020). Isolamento social vertical X Isolamento social horizontal: os dilemas sanitários e sociais no enfrentamento da pandemia de COVID-19. Brazilian Journal of Healthy Review, 3(2), 3556-3576. http://dx.doi.org/10.34119/bjhrv3n2-185.

Silva, M. R., Silva, P. C., Rabelo, H. D., \& Vinhas, B. C. V. (2020). A terapia ocupacional pediátrica brasileira diante da pandemia da COVID-19: reformulando a prática profissional. Revista Interinstitucional Brasileira de Terapia Ocupacional, 4(3), 422-437. http://dx.doi.org/10.47222/2526-3544.rbto34171.

Souza, N. L., Araújo, A. C. P. F., Costa, I. C. C., Carvalho, J. B. L., \& Silva, M. L. C. (2009). Representaçóes de mãe sobre hospitalizaçáo do filho prematuro. Revista Brasileira de Enfermagem, 62(5), 729-733.

Takatori, M. (2001). A terapia ocupacional no processo de reabilitação: construçáo do cotidiano. Mundo da Saúde, 25, 371-377.

Thiry-Cherques, R. H. (2016). Saturação em pesquisa qualitativa: estimativa empírica de dimensionamento. Revista Brasileira de Pesquisas de Marketing, Opiniāo e Mídia, 4(8), 20-27.

World Health Organization - WHO. (2020a). Mental health and COVID-19. Recuperado em 17 de maio de 2020, de https://www.who.int/teams/mental-health-and-substance-use/covid-19

World Health Organization - WHO. (2020b). Rolling updates on coronavirus disease (COVID-19). Recuperado em 17 de maio de 2020, de https:/www.who.int/emergencies/diseases/novel-coronavirus-2019

Zandifar, A., \& Badrfam, R. (2020). Iranian mental health during the COVID-19 epidemic. Asian Journal of Psychiatry, 51, 101990. http://dx.doi.org/10.1016/j.ajp.2020.101990.

\section{Contribuiçáo dos Autores}

Amanda Leâo da Silveira Rocha e Erika da Silva Dittz foram responsáveis pela elaboraçáo da proposta de estudo, análise dos dados e redação do texto. Todos os autores aprovaram a versão final do texto.

\section{Autora para Correspondência}

Amanda Leão da Silveira Rocha

e-mail: amanda.leao2@hotmail.com

\section{Editora de seçáo}

Luzia Iara Pfeifer 